\title{
Coulisses
}

Revue de théâtre

19 | Hiver 1999

Varia

\section{Coulisses et les PUFC : la création des Presses Universitaires Franc-Comtoises}

Marita Gilli

\section{OpenEdition}

1 Journals

Édition électronique

URL : https://journals.openedition.org/coulisses/5663

DOI : $10.4000 /$ coulisses.5663

ISSN : 2546-9460

Éditeur

Presses universitaires de Franche-Comté

Édition imprimée

Date de publication : 1 janvier 1999

Pagination : 52

ISBN : 2-913322-09-3

ISSN : $1150-594 \mathrm{X}$

\section{Référence électronique}

Marita Gilli, «Coulisses et les PUFC : la création des Presses Universitaires Franc-Comtoises », Coulisses [En ligne], 19 | Hiver 1999, mis en ligne le 18 octobre 2019, consulté le 12 janvier 2022. URL http://journals.openedition.org/coulisses/5663 ; DOI : https://doi.org/10.4000/coulisses.5663

Ce document a été généré automatiquement le 12 janvier 2022.

Coulisses 


\title{
Coulisses et les PUFC : la création des Presses Universitaires Franc- Comtoises
}

\author{
Marita Gilli
}

Créées en 1997, les Presses Universitaires Franc-Comtoises (PUFC) prennent place dans la politique universitaire en matière de communication et de valorisation de la recherche. Elles ont pour mission de faire connaître les travaux de l'Université, en particulier dans le domaine de la recherche, mais aussi en élargissant le champ de leurs publications à la didactique des disciplines et aux publications d'intérêt régional. Sur des bases élargies, les PUFC assurent leurs missions pour toutes les composantes de l'Université et sont l'expression de la communauté scientifique de l'Université de Franche-Comté, tant au niveau régional que national et international. 


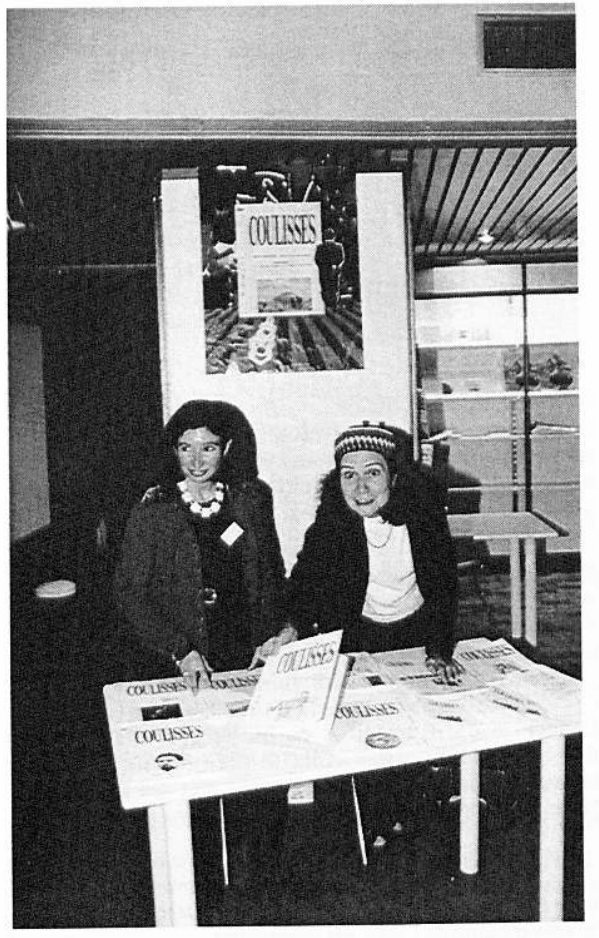

Photo Georges Pannetton

2 La création d'un service commun des publications universitaires répond à la demande du Ministère de l'Éducation Nationale qui soutient nos publications depuis 1981. Elle a été inscrite dans le Contrat d'Établissement de l'Université. L'Université de FrancheComté était l'avant-dernière à n'avoir qu'un service facultaire. Aujourd'hui, toutes les universités ont réuni leurs publications en un service commun. La création d'un tel service permet à l'Université d'avoir une politique de publications et d'assurer un fonctionnement cohérent tout en tenant compte de la diversité et de la spécificité des utilisateurs (de la revue financée par le CNRS aux ouvrages de didactique et de vulgarisation scientifique en direction des milieux locaux). La mise en commun des moyens permettra de publier moins cher et plus vite, ce qui est indispensable car, dans certains domaines, deux ans de retard peuvent rendre une publication caduque.

Dans un souci d'ouverture, les PUFC adhèrent à l'Association Française des Presses Universitaires (AFPU) et à l'Association des Nompareilles, association des éditeurs franc-comtois dont elles sont le plus gros éditeur.

Les PUFC sont dirigées par un directoire composé de quatre enseignants-chercheurs : un directeur, Marita Gilli, et trois directeurs adjoints, Jacques Annequin, Pierre-Marie Badot et Stéphane Ratti. Elles sont administrées par un conseil qui comprend vingt et un membres : le président de l'Université, le vice-président du Conseil scientifique, le directeur des PUFC, douze représentants de collections, séries et revues, trois personnels IATOS, deux personnalités extérieures, un enseignant élu au sein du C.A.

Les PUFC coiffent plusieurs collections existantes (d'autres sont en création) :

- Histoire ancienne : sept séries

- Révolution française 
- Sciences et techniques de l'environnement

- Littérature

- Géographie

- Linguistique

- Psychologie

- Annales littéraires : onze séries,

ainsi que des revues :

- BULAG

- Bulletins de l'IREM

- Cahiers du CRESLEF

- Confrontations orthophoniques

- Coulisses

- Dialogues d'histoire ancienne (revue CNRS).

\section{AUTEUR}

\section{MARITA GILLI}

Université de Franche-Comté 